\title{
Effects of uremic solutes on reactive oxygen species in vitro model systems as a possibility of support the renal function management
}

Renata P Assis ${ }^{1}$, Juliana FA Castro ${ }^{2}$, Vânia O Gutierres ${ }^{1}$, Carlos A Arcaro ${ }^{1}$, Renata S Brotto ${ }^{1}$, Olga MMF Oliveira ${ }^{2}$, Amanda M Baviera ${ }^{1}$ and Iguatemy L Brunetti ${ }^{i^{*}}$

\begin{abstract}
Background: In view of the prevalence of oxidative stress in chronic kidney disease (CKD) patients, the loss of lowmolecular-weight biomolecules by hemodialysis and the antioxidant potential of some uremic solutes that accumulate in $C K D$, we used in vitro model systems to test the antioxidant potential of the following uremic solutes: uric acid, hippuric acid, $p$-cresol, phenol, methylguanidine, L-arginine, L-tyrosine, creatinine and urea.

Methods: The in vitro antioxidant efficiencies of the uremic solutes, isolated or in mixtures, were tested with the following assays: i) ABTS radical cation decolorization assay; ii) hypochlorous acid ( $\left.\mathrm{HOCl} / \mathrm{OCl}^{-}\right)$scavenging activity; iii) superoxide anion radical $\left(\mathrm{O}_{2}^{*}\right)$ scavenging activity; iv) crocin bleaching assay (capture of peroxyl radical, $\mathrm{ROO}$ ); $v$ ) hydrogen peroxide $\left(\mathrm{H}_{2} \mathrm{O}_{2}\right)$ scavenging activity.

Results: Four of the tested uremic solutes ( $p$-cresol, phenol, L-tyrosine, uric acid) were effective antioxidants and their $I_{50}$ were found in three model systems: $\mathrm{ABTS}^{+}, \mathrm{HOCl} / \mathrm{OCl}^{-}$and crocin bleaching assay. In the 4-solutes mixtures, each one of the solute captured $12.5 \%$ for the $\mathrm{IC}_{50}$ of the mixture to $\mathrm{ABTS}^{++}$or $\mathrm{HOCl} / \mathrm{OCl}^{-}$, exhibiting a virtually exact additive effect. In the 2-solutes mixtures, for ROO capture, it was observed the need of more mass of uremic solutes to reach an $I_{50}$ value that was higher than the projected $\mathrm{IC}_{50}$, obtained from the $\mathrm{IC}_{50}$ of single solutes (25\% of each, in the binary mixtures) in the same assay. In model systems for $\mathrm{O}_{2}^{-}$and $\mathrm{H}_{2} \mathrm{O}_{2}$, none of the uremic solutes showed scavenging activity.

Conclusions: The use of the $\mathrm{IC}_{50}$ as an analytical tool to prepare and analyze mixtures allows the determination of their scavenging capacities and may be useful for the assessment of the antioxidant status of biological samples under conditions of altered levels of the endogenous antioxidant network and/or in the employment and monitoring of exogenous antioxidant therapy.
\end{abstract}

Keywords: Chronic kidney disease, Hemodialysis, Oxidative stress, Uremic solutes, $I_{50}$ as clinical chemistry tool

\section{Background}

Oxidative stress has been postulated as a cause and also an exacerbating factor of various diseases, including the chronic kidney diseases (CKD) [1]. Increased reactive oxygen species (ROS) production is often caused by the dysfunctional mitochondria formed in the most important conditions that lead to CKD [2]; impairment in the antioxidant defenses and endogenous activation of

\footnotetext{
* Correspondence: brunetti@fcfar.unesp.br

'Department of Clinical Analysis, School of Pharmaceutical Sciences, São Paulo State University - UNESP, Rua Expedicionários do Brasil 1621,

Araraquara CEP 14801-902, São Paulo, Brazil

Full list of author information is available at the end of the article
}

phagocytes have been also cited as potential factors responsible for oxidative stress in CKD [3]. Over the last years it has become clear that the association among increased ROS generation, impaired endogenous antioxidant systems and low nitric oxide (NO) bioavailability plays a crucial role in the development of the endothelial dysfunction in CKD patients $[4,5]$, predisposing them to long-term complications closely related to atherosclerosis and cardiovascular morbidity [6,7].

During the progression of the renal disease, loss of kidney function is accompanied by failing organ function leading to accumulation of a series of compounds [8]. So, in the later stages of CKD, the treatment aims to 
slow the damage progress and to compensate the impairments caused by the reduced kidney function, via a renal replacement therapy, in which hemodialysis (HD) is the most common [2,9]. The primary goal of HD is to restore the intracellular and extracellular fluid environment typical of normal kidney function [10]. However, $\mathrm{HD}$ is considered an exacerbating factor for oxidative stress in CKD patients, mainly attributed to the activation of neutrophils during forced passage of blood through the dialysis circuits, provoking endogenous inflammatory processes with release of ROS [11]. Also, loss of circulating low-molecular-weight dialyzable antioxidants is also a consequence of HD. Taken together, it is postulated that oxidative stress increases in CKD patients after HD session [12,13]. Ujhelyi and collaborators [14] found that the decreased antioxidant capacity of plasma ultrafiltrate from CKD patients on HD may be due to the dialytic removal of some uremic solutes, increasing the risk of low density lipoprotein (LDL) oxidation and subsequent endothelial cell damage.

More than 90 uremic solutes removed from blood by HD are reported, grouped according to their physicochemical properties [15]. In spite of the toxicity due to the increased levels of uremic solutes in CKD patients, it is crescent the data regarding the increased oxidative stress after HD attributable to the loss of uremic solutes [16-18], mainly uric acid. Blood levels of $\mathrm{O}_{2}^{*-}$ are raised in CKD patients and further increased after one session of HD [13]. The controversial roles of uremic solutes in CKD patients highlight to the importance of monitoring their antioxidant status, which can be useful to bring information about the oxidative stress before and after $\mathrm{HD}$, weighting the need of employing antioxidant therapy, as well to investigate the effectiveness of antioxidant interventions.

The assessment in serum of the scavenging capacity against ROS has been cited as a good indicator of the individual defenses to oppose the oxidative stress [19]. The ROS scavenging capacity in biological samples depends on the nature of the reactive species, the molecular structure of the antioxidants and the locus of this interaction. However, considering the myriad of molecules acting as antioxidant in serum samples and the interactions among them, it is often difficult to assess the relative contribution of their individual antioxidants capacities [20].

Nowadays, efforts have been made to standardize an in vitro analytical assay attempting to bring information that can expand the actual knowledge of the antioxidant effectiveness in biological samples. In this way, it seems useful to develop analytical tools that allow the determination of the antioxidant capacity of mixtures composed of endogenous and/or exogenous compounds, such as in vitro model systems. Therefore, considering that: $i)$ the uremic solutes show different antioxidant capacities and ii) the knowledge of their serum levels, we believe that the use of an analytical method that allows their individual scavenging capacity to be determined may be useful for the assessment of the oxidative status in CKD and/or HD patients, as well as for the effectiveness of antioxidant interventions. Data obtained may be useful to correlate with both the prevalence and pathogenesis of cardiovascular diseases and the continuity loss of renal function.

In this light, we investigated the antioxidant activity of the commonest uremic solutes, isolated or in selected mixtures, focusing on the involvement of certain ROS in CKD. To this end, in vitro model systems were used to assess the scavenging activity, with respect to the ABTS cation radical $\left(\right.$ ABTS $\left.^{\cdot+}\right)$, superoxide anion radical $\left(\mathrm{O}_{2}^{-*}\right)$, hypochlorous acid $(\mathrm{HOCl})$, hydrogen peroxide $(\mathrm{H} 2 \mathrm{O} 2)$ and peroxyl radical (ROO', crocin bleaching assay), exhibited by the following uremic solutes: uric acid, hippuric acid, p-cresol, phenol, methylguanidine, Larginine, L-tyrosine, creatinine and urea.

\section{Methods}

The uremic solutes creatinine, hippuric acid, uric acid, methylguanidine, L-arginine and L-tyrosine were purchased from Sigma-Aldrich, phenol and urea from Merck, and $p$-cresol from Riedel de Haën.

Besides the uremic solutes, 6-hydroxy-2,5,7,8-tetramethylchroman-2-carboxylic acid (Trolox, Sigma Aldrich, USA), a soluble synthetic analogue of vitamin E with well-established antioxidant activity [21], was used as a standard. Absorbance readings were taken in a microplate spectrophotometer (Biotek- Power Wave XS2), or an OceanOptics USB 4000 for the tests with crocin, with magnetic stirring and Peltier heating. The scavenging capacities against oxidizing species were calculated as the mean of triplicate tests, except for peroxyl radical (ROO*) scavenging assay, which was performed in duplicate assays. The concentrations reported are final concentrations in the assays.

\section{ABTS radical cation decolorization assay}

Antioxidant activity was assessed by the ABTS method, as described by Re et al. [22], with modifications. The $\mathrm{ABTS}^{*+}$ radical cation was generated by oxidation of 2,2'-azino-bis (3-ethylbenzthiazoline-6-sulphonic acid), (ABTS, Sigma Aldrich, USA) $(7 \mathrm{mmol} / \mathrm{L})$ with potassium persulfate (Sigma Aldrich, USA) $(140 \mathrm{mmol} / \mathrm{L})$ in the dark at room temperature for 12 to 16 hours. This $\mathrm{ABTS}^{*+}$ stock solution was diluted in sodium phosphate buffer $(10 \mathrm{mmol} / \mathrm{L}, \mathrm{pH} 7.0)$ to an absorbance of $0.750 \pm$ 0.020 , at $734 \mathrm{~nm}$. Various concentrations of uremic solutes were then added, the reaction mixture was incubated for 15 minutes in the dark at room temperature and absorbance was read at $734 \mathrm{~nm}$. The results were 
expressed as mean \pm standard error of the mean (SEM) of the $50 \%$ inhibitory concentration $\left(\mathrm{IC}_{50}\right)$.

\section{Superoxide anion radical $\left(\mathrm{O}_{2}^{-}\right)$scavenging assay}

The $\mathrm{O}_{2}^{*-}$ was produced by reaction between reduced nicotinamide adenine dinucleotide (NADH, Sigma Aldrich, USA), phenazine methosulfate (PMS, Sigma Aldrich, USA) and molecular oxygen [23]. The $\mathrm{O}_{2}^{*-}$ generated reacts with nitroblue tetrazolium (NBT, Sigma Aldrich, USA), reducing it to a blue formazan, whose color intensity is directly proportional to the radical concentration. The test was performed in sodium pyrophosphate buffer $(25 \mathrm{mmol} / \mathrm{L}, \mathrm{pH} 8.3)$, containing PMS $(372 \mu \mathrm{mol} / \mathrm{L})$, NBT $(600 \mu \mathrm{mol} / \mathrm{L}), \mathrm{NADH}(1560 \mu \mathrm{mol} / \mathrm{L})$ and various concentrations of uremic solutes. After 7 minutes at room temperature, the absorbance was read at $560 \mathrm{~nm}$ to determine the concentration of formazan [24]. The assay in the absence of uremic solutes was used as a control (100\% reaction) and the reaction medium without NADH was used as a reading blank. The results were expressed as mean $\mathrm{IC}_{50} \pm \mathrm{SEM}$.

\section{Hypochlorous acid $\left(\mathrm{HOCl} / \mathrm{OCl}^{-}\right)$scavenging assay}

The antioxidant activity depends on the capacity of the sample to capture $\mathrm{HOCl} / \mathrm{OCl}^{-}$, preventing it from oxidizing 3,3',5,5'- tetramethylbenzidine (TMB, Sigma Aldrich, USA). TMB oxidation by $\mathrm{HOCl} / \mathrm{OCl}^{-}$generates a blue compound with maximum absorbance at $655 \mathrm{~nm}[25,26]$.

To produce a standard solution of $\mathrm{OCl}^{-}, \mathrm{NaOCl}$ was diluted in $10 \mathrm{mmol} / \mathrm{L} \mathrm{NaOH}$ and its concentration was determined by its molar extinction coefficient $(\varepsilon=350$ $\mathrm{M}^{-1} \mathrm{~cm}^{-1}$ at $292 \mathrm{~nm}$ ) [27].

Various concentrations of uremic solutes in sodium phosphate buffer $(50 \mathrm{mmol} / \mathrm{L}, \mathrm{pH} 7.4)$ were incubated with $\mathrm{HOCl} / \mathrm{OCl}^{-}(30 \mu \mathrm{mol} / \mathrm{L})$ for 10 minutes. TMB $(2.8 \mathrm{mmol} /$ $\mathrm{L}$ dissolved in $50 \%$ dimethylformamide with $0.01 \mathrm{~mol} / \mathrm{L} \mathrm{po-}$ tassium iodide in $0.8 \mathrm{~mol} / \mathrm{L}$ acetic acid) was then added and incubated for 5 minutes at room temperature in the dark and the absorbance were monitored at $655 \mathrm{~nm}$, as described by Dypbukt [26], with modifications. The assay without uremic solutes was used as control (100\% reaction) and the absorbance of the reaction medium without $\mathrm{HOCl}$ was used as a reading blank. The results were expressed as mean $\mathrm{IC}_{50} \pm \mathrm{SEM}$.

\section{Peroxyl radical (ROO') scavenging assay}

The peroxyl radical (ROO*) is formed during the process of lipoperoxidation (LPO) in aerated medium; several model systems simulate this reaction to assess the capacity of antioxidants to scavenge this type of oxidative activity, including the protection against bleaching of crocin.

The crocin bleaching assay was performed as described by Tubaro et al. [28], by monitoring the decrease in crocin absorbance at $443 \mathrm{~nm}$ for 10 minutes, in a competitive kinetics procedure. The reaction is initiated by addition of the azo-compound 2,2'-azobis(2-amidinopropane) dihydrochloride (AAPH, Sigma Aldrich, USA), which by thermolysis at $40^{\circ} \mathrm{C}$, generates peroxyl radicals at a constant rate.

Thus, the antioxidants compete with the crocin for ROO; therefore, the inhibition of its oxidation depends on the capacity of samples in capture the radical species (Scheme 1).

To perform this test, the molar extinction coefficient $(\varepsilon)$ of crocin in DMSO was determined, as this solvent was used to enhance its solubility and prepare the crocin stock solution: $\varepsilon=13,726 \mathrm{M}^{-1} \mathrm{~cm}^{-1}$, at $443 \mathrm{~nm}$.

The crocin $(25 \mu \mathrm{mol} / \mathrm{L}$, Sigma Aldrich, USA) in sodium phosphate buffer $120 \mathrm{mmol} / \mathrm{L}, \mathrm{pH} 7.0$, was mixed with various concentrations of uremic solutes. The reaction was started by adding $12.5 \mathrm{mmol} / \mathrm{L}$ of $\mathrm{AAPH}$ and performed at $40^{\circ} \mathrm{C}$ with constant stirring. The rate of crocin bleaching (linear after about 1 minute of reaction) was monitored at $443 \mathrm{~nm}$ for 10 minutes. To eliminate possible interference from the sample, a reaction mixture without crocin was prepared for each solute and used as the reaction blank.

The rate of crocin bleaching by the generated peroxyl radical $\left(\mathrm{v}_{0}\right)$ decreases in the presence of an antioxidant, as it competes with the crocin for the peroxyl radical, and the new bleaching rate $(\mathrm{v})$ is given by:

$$
\mathrm{v}=\mathrm{v}_{0} \times \frac{\mathrm{kc}[\mathrm{C}]}{\mathrm{kc}[\mathrm{C}]+\mathrm{ka}[\mathrm{A}]}
$$

where: $\mathrm{v}_{0}=\mathrm{k}_{1} \times$ [ROO $^{*} \mathrm{x}[\mathrm{C}] ; \mathrm{kc}=\mathrm{k}_{1} \times\left[\mathrm{ROO}^{*}\right] ; \mathrm{ka}=\mathrm{k}_{2} \mathrm{x}$ $\left[\mathrm{ROO}^{*}\right] ;\left[\mathrm{ROO}^{*}\right]=$ concentration of peroxyl radical; $\mathrm{v}_{0}=\mathrm{re}-$ action rate between crocin and $\mathrm{ROO}^{\circ} ; \mathrm{k}_{1}=$ rate constant

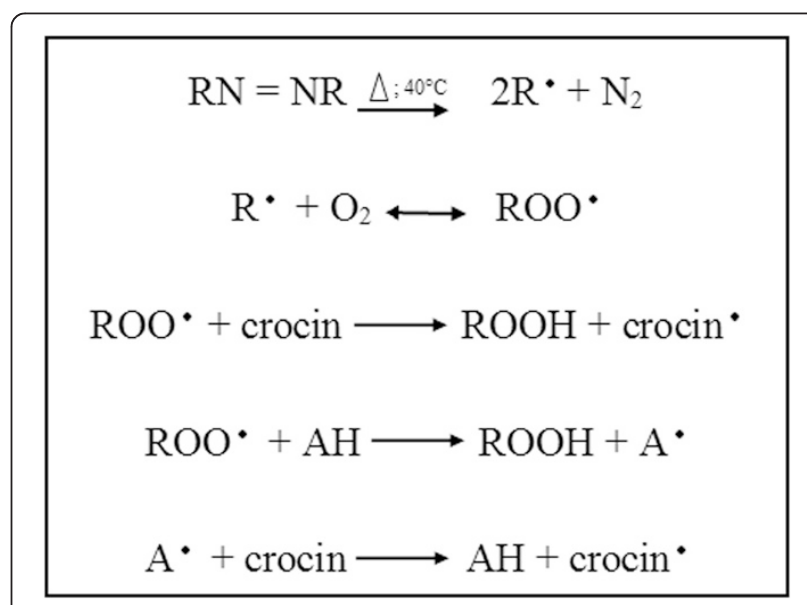

Scheme 1 Reactions involved in the crocin bleaching with termolysis of AAPH (adapted from Ordoudi and Tsimidou [58]. A, represents an antioxidant (sample). 
Table 1 Uremic solute concentrations ( $\mathrm{mmol} / \mathrm{L}$ )

\begin{tabular}{lcc}
\hline & Uremic concentration (UC) & Physiological concentration (PC) \\
\hline 1- L-arginine & 0.230 & 0.140 \\
2- Creatinine & 0.880 & 0.120 \\
3- -cresol & 0.280 & 0.021 \\
4- Hippuric acid & 1.700 & 0.028 \\
5- Methylguanidine & 0.091 & 0.006 \\
6- Phenol & 0.110 & 0.015 \\
7- L-tyrosine & 0.110 & 0.027 \\
8- Urea & 33.000 & 6.700 \\
9- Uric acid & 0.600 & 0.420 \\
\hline 1 - UC [59], PC [60]; 2 UC [61], PC [62]; 3 - UC [63], PC [64]; 4 - UC [61], PC [65]; 5 - UC [66], PC [66]; 6 - UC [67], PC [65]; 7- UC [68], PC [69]; 8 - UC [70], PC [62]; 9
\end{tabular}

for the $\mathrm{ROO}^{\circ}$-crocin reaction; $\mathrm{k}_{2}=$ rate constant for the ROO $^{\circ}$-antioxidant reaction; $[\mathrm{C}]=$ crocin concentration; [A] = antioxidant (uremic solute) concentration.

The fall in crocin bleaching rate in the presence of an antioxidant can be modeled as follows:

$$
\frac{\mathrm{v}_{0}}{\mathrm{v}}=\frac{\mathrm{kc}[\mathrm{C}]+\mathrm{ka}[\mathrm{A}]}{\mathrm{kc}[\mathrm{C}]}=1+\frac{\mathrm{ka}}{\mathrm{kc}} \times \frac{[\mathrm{A}]}{[\mathrm{C}]}
$$

from the above equation,

The coefficient $\mathrm{ka} / \mathrm{kc}$, calculated as the slope of the regression line for the $\mathrm{v}_{0} / \mathrm{v}$ versus $[\mathrm{A}] /[\mathrm{C}]$ plot, indicates the relative capacity of an antioxidant to interact with the peroxyl radicals. By dividing this slope for a uremic solute by the slope for a standard antioxidant such as Trolox, the ratio of rate constants, and thus the relative antioxidant capacity, of the analyzed compound can be estimated, being expressed in Trolox equivalents.

\section{Hydrogen peroxide scavenging assay}

The $\mathrm{H}_{2} \mathrm{O}_{2}$ (Merck, German) oxidizes 2-nitro-5-thiobenzoic acid (TNB, Sigma Aldrich, USA) to 5,5' -dithiobis2-nitrobenzoic acid (DTNB), with a decrease in absorbance at $412 \mathrm{~nm}$ and increase at $325 \mathrm{~nm}$ [29].

The TNB solution was prepared by the method of Ching et al. [30]; in $50 \mathrm{mmol} / \mathrm{L}$ potassium phosphate buffer ( $\mathrm{pH}$ 6.6) and its concentration was determined from its molar extinction coefficient at $412 \mathrm{~nm}(13,600$ $\mathrm{M}^{-1} \mathrm{~cm}^{-1}$; [31]); $\mathrm{H}_{2} \mathrm{O}_{2}$ concentration was determined as described by Brestel [32], $\left(\varepsilon=80 \mathrm{M}^{-1} \mathrm{~cm}^{-1}\right.$, at $\left.230 \mathrm{~nm}\right)$.

In $50 \mathrm{mmol} / \mathrm{L}$ potassium phosphate buffer $\mathrm{pH}$ 6.6, various concentrations of uremic solutes were incubated with $\mathrm{H}_{2} \mathrm{O}_{2}(0.3 \mathrm{mmol} / \mathrm{L})$ for 30 minutes at $37^{\circ} \mathrm{C}$. TNB (53 $\mu \mathrm{mol} / \mathrm{L}$ ) was added and incubated for 1 hour at $37^{\circ} \mathrm{C}$. The absorbance was read at $412 \mathrm{~nm}$. Catalase (20 units $/ \mathrm{mL}$ ) was used as a standard $\mathrm{H}_{2} \mathrm{O}_{2}$ scavenging agent.

The percent inhibition of TNB oxidation, i.e., percent $\mathrm{H}_{2} \mathrm{O}_{2}$ capture, was calculated from the difference in absorbance between reaction mixtures with and without uremic solutes.

\section{Experiments with uremic solute mixtures}

In view of the observed effectiveness of some of the uremic solutes, viz. uric acid, $p$-cresol, phenol and Ltyrosine, in assays with $\mathrm{ABTS}^{*+}, \mathrm{HOCl} / \mathrm{OCl}^{-}$or $\mathrm{ROO}^{*}$, further assays of their ability to scavenge these reactive species were performed on mixtures of these four solutes, in proportions based on their respective $\mathrm{IC}_{50}$.

These test mixtures were so designed that each of the 4 (or 2) solutes was present in the same proportion as its $\mathrm{IC}_{50}$; thus, fractions or multiples of this volume would correspond to the same fractions or multiples of the $\mathrm{IC}_{50}$ of each of the uremic solutes. With this procedure, if the scavenging effect of the solute mixture shows independent activities of solutes, it would be additive and exact, therefore the $\mathrm{IC}_{50}$ of the mixture would contain ROS-scavenging activities of each component at $12.5 \%$ or $25 \%$ for 4 or 2 solutes, respectively, of its individual $\mathrm{IC}_{50}$.

\section{Results}

In vitro model systems were used to assay the antioxidant activity against the reactive species: $\mathrm{ABTS}^{\bullet+}, \mathrm{O}_{2}^{\bullet-}$, $\mathrm{H}_{2} \mathrm{O}_{2}, \mathrm{HOCl} / \mathrm{OCl}^{-}$and $\mathrm{ROO}^{\circ}$ (crocin bleaching assay). The assays were performed with uremic solutes at various concentrations, chosen in relation to the upper limit of the respective reference range for healthy people (physiological concentration) and those found in the serum of patients with CKD (mean uremic concentration), as listed in Table 1. The uremic solutes were chosen according to the following criterion: $i$ ) classification according to the size and binding properties [33]; ii) highest uremic concentration/normal concentration ratio [33]; iii) knowing antioxidant capacity of some uremic solutes $[14,34,35]$. 

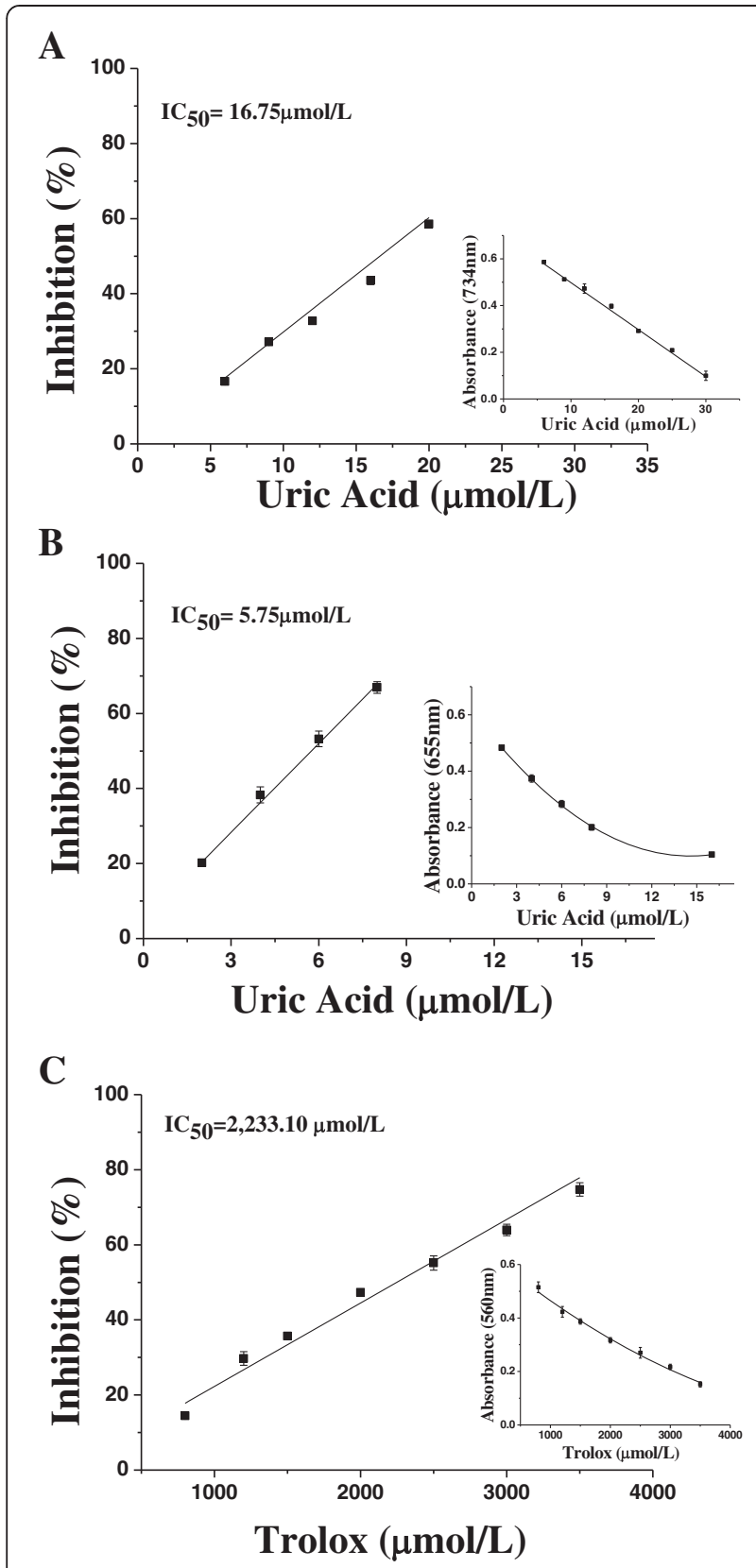

Figure 1 Scavenging capacity of the uric acid and Trolox on the ROS. (A) ABTS ${ }^{++}$scavenging capacity $\left(I C_{50}\right)$ of uric acid. The graph inset shows the mean absorbance of $\mathrm{ABTS}^{+}$, at $734 \mathrm{~nm}$, for various concentrations of uric acid. (B) $\mathrm{HOCl} / \mathrm{OCl}^{-}$scavenging capacity $\left(\mathrm{IC}_{50}\right)$ of uric acid. The inset shows the mean absorbance of $\mathrm{HOCl} / \mathrm{OCl}^{-}$, at $655 \mathrm{~nm}$, for various concentrations of uric acid. (C) $\mathrm{O}_{2}^{-}$scavenging capacity $\left(\mathrm{IC}_{50}\right)$ of Trolox. The inset shows the mean absorbance of $\mathrm{O}_{2}^{-}$, at $560 \mathrm{~nm}$, for various concentrations of Trolox. The scavenging capacities against oxidizing species were performed in triplicate tests.

\section{$\mathrm{ABTS}^{++}$radical scavenging by uremic solutes}

In the $\mathrm{ABTS}^{\circ+}$ assay, the Trolox (standard) showed an $\mathrm{IC}_{50}$ value of $16.45 \pm 0.30 \mu \mathrm{mol} / \mathrm{L}$. Uric acid, with an
$\mathrm{IC}_{50}$ of $16.75 \pm 0.14 \mu \mathrm{mol} / \mathrm{L}$ (Figure $1 \mathrm{~A}$ ) for $\mathrm{ABTS}^{\bullet+}$, was as effective an antioxidant as Trolox.

The other solutes (Table 2) also show efficiency against ABTS $^{*+}$, with $\mathrm{IC}_{50}$ ranging from $4 \mu \mathrm{mol} / \mathrm{L}$ to $61 \mathrm{mmol} / \mathrm{L}$ or higher: $p$-cresol < L-tyrosine $<$ phenol $<$ uric acid < creatinine $<\mathrm{L}$-arginine. Hippuric acid, methylguanidine and urea did not have any effect on $\mathrm{ABTS}^{*+}$ at the tested concentrations.

\section{$\mathrm{HOCl} / \mathrm{OCl}^{-}$scavenging by uremic solutes}

In the $\mathrm{HOCl} / \mathrm{OCl}^{-}$assay, most of the uremic solutes proved to be effective in scavenging this ROS and, therefore, it was possible to measure their $\mathrm{IC}_{50}$ (Figure 1B). However, methylguanidine, even at up to 10 times the average uremic plasma level, had no effect on $\mathrm{HOCl} /$ $\mathrm{OCl}^{-}$. Trolox was used as the standard, with an $\mathrm{IC}_{50}=$ $8.65 \pm 0.39 \mu \mathrm{mol} / \mathrm{L}$. Table 2 presents the values of $\mathrm{IC}_{50}$ for uremic solutes in this assay, from approximately 3 $\mu \mathrm{mol} / \mathrm{L}$ up to $92 \mathrm{mmol} / \mathrm{L}$ or higher; the ascending order of $\mathrm{IC}_{50}$ was: L-tyrosine $<$ uric acid $<$ phenol $<p$-cresol $<$ hippuric acid $<$ urea $<$ creatinine $<$ L-arginine (descending order of effectiveness).

\section{$\mathrm{O}_{2}^{--}$scavenging by uremic solutes}

The uremic solutes were tested at three concentrations: physiological, uremic and 10 times the average uremic level. None of the tested solutes were effective in scavenging $\mathrm{O}_{2}^{*-}$ at any tested concentration. Again, Trolox was used as a standard, showing a relatively high value of $\mathrm{IC}_{50}(\approx 2 \mathrm{mmol} / \mathrm{L})$, but demonstrating that the test was valid (Figure 1C).

\section{$\mathrm{H}_{2} \mathrm{O}_{2}$ scavenging by uremic solutes}

None of the uremic solutes at physiological, or up to 10 times uremic concentrations, or even Trolox (up to 6 $\mathrm{mmol} / \mathrm{L}$ ), captured $\mathrm{H}_{2} \mathrm{O}_{2}$ (data not shown), so we used catalase to validate the test, because of its recognized efficiency and specificity in converting $\mathrm{H}_{2} \mathrm{O}_{2}$ to water and oxygen [21]; for this enzyme, an $\mathrm{IC}_{50}$ of 0.55 units $/ \mathrm{mL}$ or $18.6 \mu \mathrm{g} / \mathrm{mL}(77.5 \mathrm{nmol} / \mathrm{L}$, considering the molecular weight, 240,000 Da [36]) was observed.

\section{ROO` scavenging by uremic solutes}

The ability of Trolox to inhibit crocin bleaching is shown in Figure 2A. Comparing the values of the slope (reaction rate) for the uremic solutes, the order of decreasing antioxidant capacity was: uric acid $>p$-cresol $>$ phenol > L-tyrosine (e.g. see Figure 2B, C, D, E). In the presence of all the other solutes, the crocin bleaching rate was unchanged, indicating a lack of interaction with the peroxyl radical and, therefore, that these solutes did not show antioxidant capacity against ROO'.

It is also possible to assess crocin bleaching in another way, by determining the percent inhibition of crocin 
Table 2 ROS scavenging activities of uremic solutes, expressed as concentration needed for $\mathbf{5 0 \%}$ inhibition $\left(\mathrm{IC}_{50} \pm \mathrm{SEM}^{*}, \mu \mathrm{mol} / \mathrm{L}\right)$

\begin{tabular}{|c|c|c|c|c|c|}
\hline Solutes & $\mathrm{ABTS}^{+}$ & $\mathrm{O}_{2}^{-}$ & $\mathrm{H}_{2} \mathrm{O}_{2}^{* * *}$ & $\mathrm{HOCl} / \mathrm{OCl}^{-}$ & Crocin bleaching assay \\
\hline L-arginine & $61,350.00 \pm 562.56$ & $* *$ & ** & $92,100.00 \pm 0.10$ & ** \\
\hline Creatinine & $536.26 \pm 3.32$ & $* *$ & $* *$ & $9,130.00 \pm 0.10$ & $* *$ \\
\hline$p$-cresol & $3.99 \pm 0.01$ & $* *$ & $* *$ & $15.75 \pm 0.12$ & $1,162.31$ \\
\hline Hippuric acid & $* *$ & $* *$ & $* *$ & $1,600.00 \pm 0.01$ & $* *$ \\
\hline Methylguanidine & $* *$ & $* *$ & $* *$ & $* *$ & $* *$ \\
\hline Phenol & $12.98 \pm 0.09$ & $* *$ & $* *$ & $8.95 \pm 0.10$ & $1,125.81$ \\
\hline Trolox & $16.45 \pm 0.30$ & $2,223.10 \pm 0.17$ & $* *$ & $8.65 \pm 0.27$ & 10.09 \\
\hline L-tyrosine & $5.23 \pm 0.02$ & $* *$ & $* *$ & $2.83 \pm 0.04$ & $* *$ \\
\hline Urea & $* *$ & $* *$ & $* *$ & $5,600.00 \pm 0.20$ & $* *$ \\
\hline Uric acid & $16.75 \pm 0.14$ & $* *$ & $* *$ & $5.75 \pm 0.13$ & 6.90 \\
\hline
\end{tabular}

Values in $\mu \mathrm{mol} / \mathrm{L}$ of $\mathrm{IC}_{50}$ of solutes; ${ }^{*}$ SEM (standard error of the mean); ${ }^{* *}$ No effect at the concentration used; *** Method was validated by reaction of $\mathrm{H}_{2} \mathrm{O}_{2}$ with catalase.

bleaching (\%In) [37] and thus the $\mathrm{IC}_{50}$. It is observed that the $\mathrm{IC}_{50}$ values found for Trolox and uremic solutes follow the same order of efficiency as the values of the slopes in the competitive test (the lower the $\mathrm{IC}_{50}$ value, the more efficient was the sample, and the greater the slope of the reaction rate regression line, showing stronger antioxidant activity) (Table 3).

It can be seen that uric acid, Trolox, phenol and $p$-cresol exhibited significant antioxidant effects, while the other solutes did not. It should be noted that only uric acid produced an effect of the same order of magnitude as Trolox, which shows its importance for the model system of LPO, since its $\mathrm{IC}_{50}$ was lower than the physiological concentration and its activity was approximately twice that of Trolox (Table 3).

\section{Oxidant scavenging of uremic solute mixtures}

Considering the four solutes: uric acid, $p$-cresol, phenol and L-tyrosine that exhibited significant scavenging capacity towards the three reactive species $\mathrm{ABTS}^{*+}, \mathrm{HOCl} /$ $\mathrm{OCl}^{-}$and $\mathrm{ROO}^{\circ}$, we performed the assays with mixtures. Therefore, the antioxidant behaviors of the mixtures of these solutes were investigated, using the $\mathrm{IC}_{50}$ of each solute against each ROS as a reference.

In the $\mathrm{ABTS}^{*+}$ or $\mathrm{HOCl} / \mathrm{OCl}^{-}$scavenging assays for 4solutes mixtures, it was found practically the projected volume of solute mixture needed for $\mathrm{IC}_{50}(39.85 \mu \mathrm{L}$ and $41.70 \mu \mathrm{L}$, respectively) (Figure $3 \mathrm{~A}$ and $\mathrm{B}$ ). For both assays, the concentration of each solute is presented in Table $4 \mathrm{~A}$ and $\mathrm{B}$, which represented about a quarter of its individual $\mathrm{IC}_{50}$.

In the crocin bleaching assay, it was used to binary mixtures: uric acid + phenol; uric acid $+p$-cresol; phenol $+p$ cresol, then it was found a high volume of solute mixture needed for $\mathrm{IC}_{50}(150.3 \mu \mathrm{L}, 126.5 \mu \mathrm{L}, 152.5 \mu \mathrm{L}$, respectively) (Figure 4A, B, C and Table 5).

\section{Discussion}

In view of the quali-quantitatively wide variation of uremic solutes found in biological fluids, and the ability of some of these solutes to scavenge certain ROS, we employed a broad set of measures of antioxidant capacity, rather than a single measure, to obtain a highly representative result. These analytical techniques were chosen to reflect, as accurately as possible, the antioxidant capacity of uremic solutes. Data from this study showed that the uremic solutes $p$-cresol, phenol, Ltyrosine and uric acid were effective antioxidants, mainly through three model systems: $\mathrm{ABTS}^{*+}, \mathrm{HOCl} / \mathrm{OCl}^{-}$and crocin bleaching assay (Table 2). When mixtures of these solutes where studied, it was found that, in 4-solutes mixtures, each one of the solute captured $12.5 \%$ for the $\mathrm{IC}_{50}$ in $\mathrm{ABTS}^{\cdot+}$ or $\mathrm{HOCl} / \mathrm{OCl}^{-}$assays (Table $4 \mathrm{~A}$ and $\mathrm{B}$ ), exhibiting a virtually exact additive effect; in 2-solutes mixtures for ROO ${ }^{*}$ capture, it was observed the need of more mass of uremic solutes to reach an $\mathrm{IC}_{50}$ value of mixtures, which was higher than the projected $\mathrm{IC}_{50}$ obtained from the $\mathrm{IC}_{50}$ of single solutes $(25 \%$ of each, in the binary mixtures) (Table 5).

In the $\mathrm{ABTS}^{\circ+}$ assay, Trolox was used as "standard" and showed an $\mathrm{IC}_{50}$ value similar that found with uric acid (Figure 1A), as also noted by others [38,39]. In a study of Gülçin [40], $79.90 \mu \mathrm{mol} / \mathrm{L}$ Trolox and 110.37 $\mu \mathrm{mol} / \mathrm{L}$ L-tyrosine both proved to be effective, scavenging $95 \%$ and $62 \%$ of $\mathrm{ABTS}^{\circ+}$, respectively. The presence of hydroxyl groups and aromatic rings in the uremic solutes appears to be correlated with their antioxidant activity, since the most effective solutes were $p$-cresol, Ltyrosine, phenol and uric acid (Table 2); this relationship between structure and antioxidant capacity of compounds has also been reported by others [40,41].

Mayer et al. [16] investigated the effect of HD on the antioxidant capacity of serum patients using the ABTS ${ }^{\cdot+}$ assay. The authors observed a decrease in serum total 

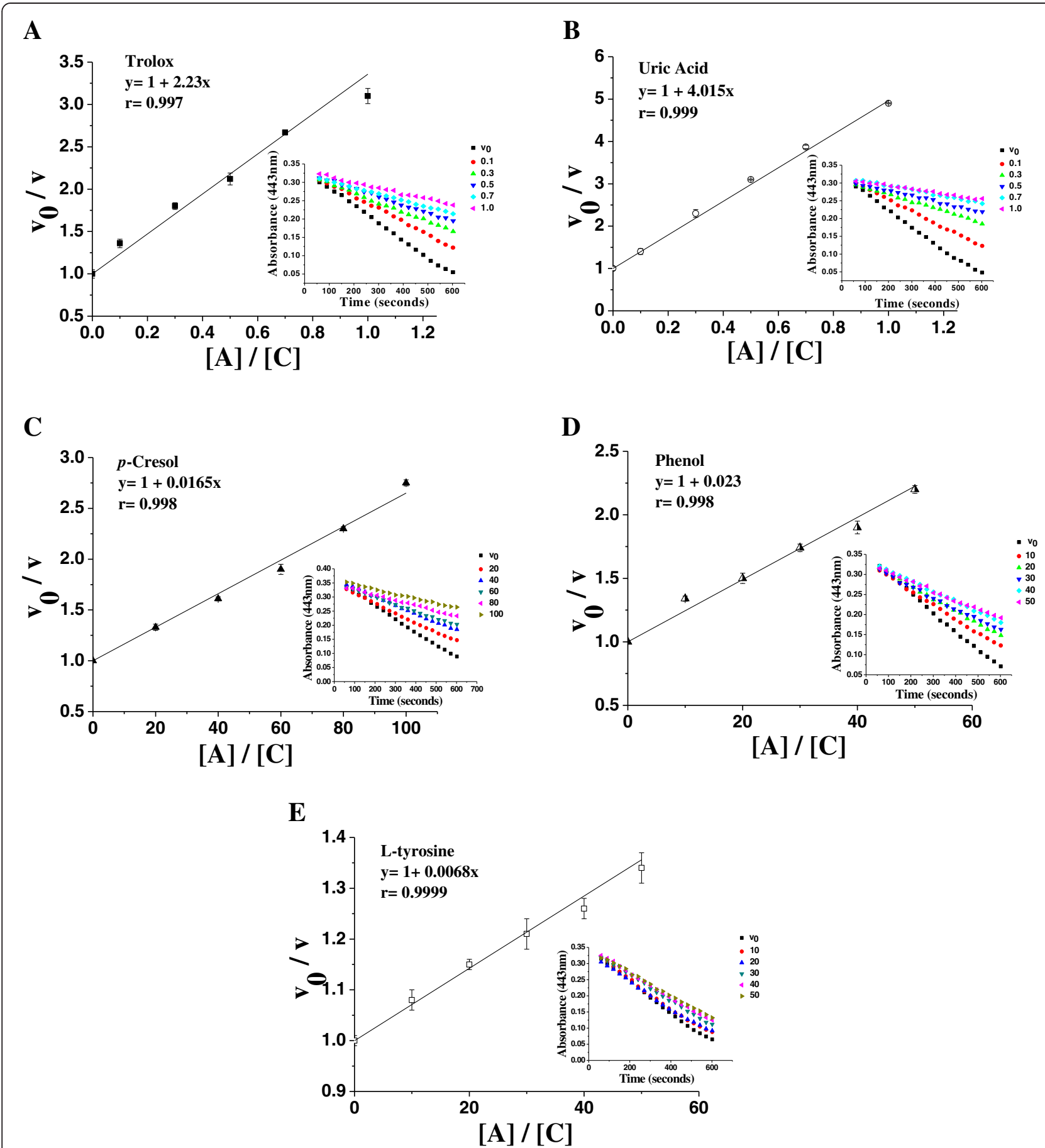

Figure 2 Reaction velocity ratios plotted against uremic solute (sample) concentrations in the crocin bleaching assay. (A) Trolox; (B) uric acid; (C) p-cresol; (D) phenol; (E) L-tyrosine. [C], crocin concentration and [A], sample concentration. The inset shows the decrease in absorbance of crocin, at $443 \mathrm{~nm}$, over $10 \mathrm{~min}$ : $\left(\mathrm{V}_{0}\right)$ velocity in the absence and $(\mathrm{v})$ velocity in the presence of various concentrations of samples. The experimental conditions are described in Methods. The ROO' scavenging assay was performed in duplicate testes.

antioxidant capacity during the HD treatment, which was attributed to the dialytic removal of uric acid and ascorbic acid. Similarly, Bianchi et al. [42] investigated the consequences of an HD session on the systemic oxidative stress of CKD patients, assaying serum samples with the total reactive antioxidant potential (TRAP) test; when pre- and post-HD sera of CKD patients were compared, it was observed a reduction in TRAP after one HD session. 
Table 3 Comparison between competitive kinetic slopes and $\mathrm{IC}_{50}$, for the crocin bleaching assay

\begin{tabular}{lll}
\hline Solutes & Slope of regression line & $\mathbf{I C}_{\mathbf{5 0}}\left(\boldsymbol{\mu \mathrm { mol } / \mathrm { L } ) ^ { * * }}\right.$ \\
\hline Uric acid & 4.015 & 6.90 \\
Trolox & 2.230 & 10.09 \\
Phenol & 0.023 & $1,125.81$ \\
p-cresol & 0.016 & $1,162.31$ \\
L-tyrosine & 0.007 & $* * *$ \\
Methylguanidine & $9.272 \times 10^{-4}$ & $* * *$ \\
L-arginine & $7.727 \times 10^{-4}$ & $* * *$ \\
Hippuric acid & $8.000 \times 10^{-5}$ & $* * *$ \\
Creatinine & $6.776 \times 10^{-5}$ & $* * *$ \\
Urea & $2.558 \times 10^{-6}$ & $* * *$
\end{tabular}

${ }^{*}$ Regression line slopes in order of decreasing efficacy; ${ }^{*} \mid \mathrm{C}_{50}$ in order of decreasing efficacy, from plot of equation: $\% \ln =\left(1-\left(\Delta \mathrm{v} / \Delta \mathrm{v}_{\mathrm{o}}\right)\right) \times 100$; ${ }^{* * *} \mid \mathrm{C}_{50}>$ highest concentration tested.

Most of the uremic solutes proved to be effective in capture $\mathrm{HOCl} / \mathrm{OCl}^{-}$, with exception of methylguanidine, which showed no effect (Table 2). The relationship of uremic solutes with $\mathrm{HOCl} / \mathrm{OCl}^{-}$system seems to be relevant when we consider the data about the increase in both the activity and concentration of myeloperoxidase (MPO) in HD patients when compared with pre-HD and control subjects [43,44]. Increased MPO activity in HD patients may be due to the activation of neutrophils during the forced blood passage through the dialysis circuits, which is related to the precocity and prevalence of atherosclerotic disease in CKD patients. In fact, increased levels of proteins modified by $\mathrm{HOCl}$ generated by the $\mathrm{MPO} / \mathrm{H}_{2} \mathrm{O}_{2} / \mathrm{Cl}^{-}$system have been found in serum of HD patients, such as oxidized albumin; $\mathrm{HOCl}$-modified albumin impairs the association of highdensity lipoprotein (HDL) with the scavenger receptor class $B$ type I, which have a protective role against atherosclerotic cardiovascular disease [45]; also, it was found a direct relationship between plasma levels of oxidized low density lipoprotein (ox-LDL) and MPO in CKD diabetic patients during HD [46]. On the other hand, whereas most of the uremic solutes scavenged $\mathrm{ABTS}^{*+}$ and $\mathrm{HOCl} / \mathrm{OCl}^{-}$effectively, the same did not happen with the other biological ROS, $\mathrm{O}_{2}^{*-}$ and $\mathrm{H}_{2} \mathrm{O}_{2}$ (Table 2).

$\mathrm{O}_{2}^{--}$is an essential ROS, since it is a precursor for other reactive species and it is constantly produced in the human body during physiological processes, such as the mitochondrial electron transport chain and some signaling events in the vascular system [21]. Its production is also initiated in activated phagocytes into the oxidative burst, leading to the synthesis of $\mathrm{O}_{2}^{--}$and other ROS, overcoming the local antioxidant capacity $[21,47]$. Thus, increased $\mathrm{O}_{2}^{--}$levels can, for example, contribute greatly to the endothelial dysfunction and thus hinder the process of vascular wall distention by scavenging $\mathrm{NO}$ to generate peroxynitrite $[7,21]$. In this context, the main mechanism by which L-arginine leads to beneficial effects on CKD has been attributed to an increase in the NO production, since nitric oxide synthase (NOS) activity in kidney failure is determined by $\mathrm{L}$-arginine concentration [48]; so, L-arginine in CKD is important to oppose endothelial dysfunction. In a review by Baylis [49], it is pointed that the total NO production is decreased in CKD patients due to main possible causes: $i$ ) the limitation of substrate (L-arginine) for NOS, and $i$ ) the increased levels of circulating endogenous inhibitors of NOS, particularly asymmetric dimethylarginine.

According our data, none of the tested solutes were effective in scavenging $\mathrm{O}_{2}^{--}$at any tested concentration (Table 2). Our results corroborate those of Barreiros et al.

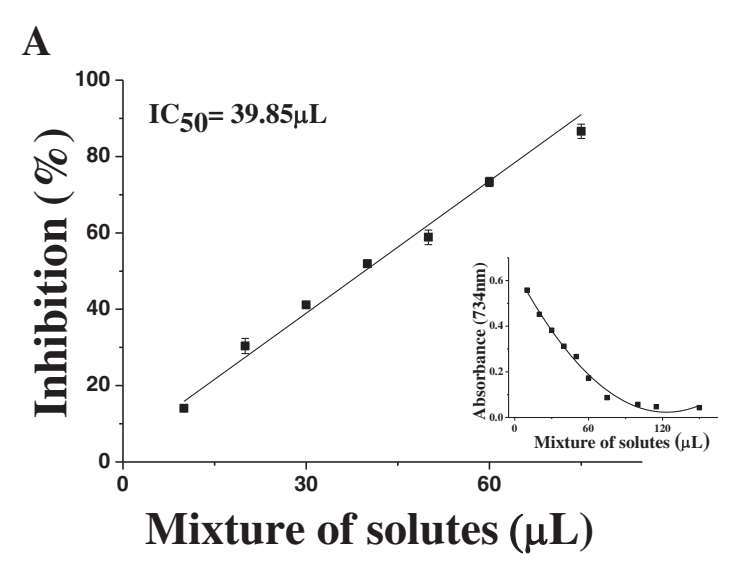

B

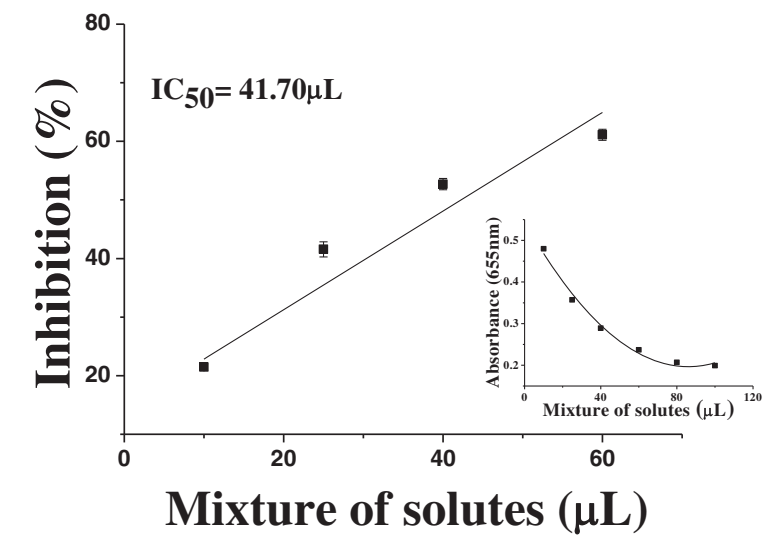

Figure 3 Capacity of the mixture of solutes uric acid, phenol, $p$ cresol and $\mathrm{L}$-tyrosine to scavenge (A) $\mathrm{ABTS}^{++}$and (B) $\mathrm{HOCl} / \mathrm{OCl}^{-}$. The inset of the figure $(\mathbf{A})$ show the mean absorbance of $\mathrm{ABTS}^{++}$, at 734 $\mathrm{nm}$, for various volumes in the assay of the stock solute mixture with: uric acid $(33.5 \mu \mathrm{mol} / \mathrm{L})$, phenol $(25.96 \mu \mathrm{mol} / \mathrm{L}), p$-cresol $(7.98$ $\mu \mathrm{mol} / \mathrm{L})$ and $\mathrm{L}$-tyrosine $(10.46 \mu \mathrm{mol} / \mathrm{L})$; final volume reaction, $300 \mu \mathrm{L}$. The inset of the figure (B) show the mean absorbance of $\mathrm{HOCl} / \mathrm{OCl}^{-}$, at $655 \mathrm{~nm}$, for various volumes in the assay of the stock solute mixture with: uric acid $(57.5 \mu \mathrm{mol} / \mathrm{L})$, phenol $(89.5 \mu \mathrm{mol} / \mathrm{L}), p$-cresol $(157.5 \mu \mathrm{mol} / \mathrm{L})$ and $\mathrm{L}$-tyrosine $(28.3 \mu \mathrm{mol} / \mathrm{L})$; final volume reaction, $1500 \mu \mathrm{L}$. The scavenging capacities against oxidizing species were performed in triplicate tests. 
Table 4 Relations between the IC 50 of the solutes uric acid, phenol, $p$-cresol and L-tyrosine for their scavenging of: (A) $\mathrm{ABTS}^{\circ+}$, (B) $\mathrm{HOCl} / \mathrm{OCl}^{-}$and the $\mathrm{IC}_{50}$ of mixed samples

\begin{tabular}{|c|c|c|c|c|}
\hline $\begin{array}{l}\text { Uremic solutes } \\
\text { in mixture }\end{array}$ & $\begin{array}{l}\text { Volume }(\mu \mathrm{L}) \text { of solute } \\
\text { mixture needed for } \mathrm{IC}_{50}\end{array}$ & $\begin{array}{l}\text { Concentration }(\mu \mathrm{mol} / \mathrm{L}) \\
\text { of each solute in mixture } \\
\text { at } \mathrm{IC}_{50}\end{array}$ & $\begin{array}{l}\mathrm{IC}_{50}(\mu \mathrm{mol} / \mathrm{L}) \text { of } \\
\text { single solutes }\end{array}$ & $\begin{array}{l}\text { Ratio of concentration of each } \\
\text { solute in the } I C_{50} \text { of the mixture } \\
\text { to its respective } I C_{50} \text {, for } A B T S^{*+}\end{array}$ \\
\hline$\overline{\mathrm{A}}$ & ABTS $^{-+}$ & ABTS $^{+}$ & ABTS $^{-+}$ & ABTS $^{++}$ \\
\hline$p$-cresol & & 1.06 & 3.99 & 0.26 \\
\hline L-tyrosine & & 1.39 & 5.23 & 0.26 \\
\hline Phenol & 39.85 & 3.45 & 12.98 & 0.26 \\
\hline Uric acid & & 4.45 & 16.75 & 0.26 \\
\hline B & $\mathrm{HOCl} / \mathrm{OCl}^{-}$ & $\mathrm{HOCl} / \mathrm{OCl}^{-}$ & $\mathrm{HOCl} / \mathrm{OCl}^{-}$ & $\mathrm{HOCl} / \mathrm{OCl}^{-}$ \\
\hline L-tyrosine & & 0.78 & 2.83 & 0.27 \\
\hline Uric acid & & 1.60 & 5.75 & 0.27 \\
\hline Phenol & 41.70 & 2.50 & 8.95 & 0.27 \\
\hline$p$-cresol & & 4.38 & 15.75 & 0.27 \\
\hline
\end{tabular}

[50], which reported that uric acid was inert against $\mathrm{O}_{2}^{--}$ and $\mathrm{H}_{2} \mathrm{O}_{2}$, but showed strong reactivity with $\mathrm{ROO}^{\circ}$ and $\mathrm{NO}_{2}^{\circ}$. In view of the high activity against $\mathrm{ROO}^{\circ}$, it has been postulated that uric acid protects lipids and DNA from the interaction with $\mathrm{ROO}^{\circ}$. While our findings of $\mathrm{O}_{2}^{--}$scavenging indicated that Trolox has a high $\mathrm{IC}_{50}$, (Figure 1C), Ak and Gülçin [51] and Gülçin [40] reported a greater efficiency of Trolox against $\mathrm{O}_{2}^{*-}$, when they used a more sensitive chemiluminescent method, with inhibition of $78.2 \%$ of $\mathrm{O}_{2}^{*-}$ activity at $39.95 \mu \mathrm{mol} / \mathrm{L}$, indicating that these differences may be attributed to methodological sensitivity.

Miyamoto et al. [35] showed that the uremic solutes uric acid, $p$-cresol and indoxyl sulfate, under physiological concentrations, they have potent antioxidant activity, comparable to that of superoxide dismutase, assessed by luminol chemiluminescence, which represents the ability to scavenge $\mathrm{O}_{2}^{*-}$. In this study, $\mathrm{O}_{2}^{--}$was generated from the xanthine/xanthine oxidase system, and the authors found that, at least for indoxyl sulfate, it did not inhibit the xanthine oxidase activity, confirming that the antioxidant property of this solute is exclusively due to its capacity to scavenge $\mathrm{O}_{2}^{*-}$.

$\mathrm{H}_{2} \mathrm{O}_{2}$ is produced in vivo continuously in virtually all tissues. The mitochondria can contribute with the cellular generation of $\mathrm{H}_{2} \mathrm{O}_{2}$, by both monoamine oxidase activity and dismutation of $\mathrm{O}_{2}^{--}$generated in the electron transport chain, although mitochondria can also consume $\mathrm{H}_{2} \mathrm{O}_{2}$; thus, in in vivo systems, $\mathrm{H}_{2} \mathrm{O}_{2}$ is generated by $\mathrm{O}_{2}^{--}$dismutation, spontaneously or catalyzed by superoxide dismutase, as well as by $\beta$-oxidation of fatty acids or directly by various oxidase enzymes [21]. None of the uremic solutes or even Trolox at high levels captured $\mathrm{H}_{2} \mathrm{O}_{2}$ (data not shown) (Table 2).

Lipid bilayer cell membranes are the main targets of attack by free radicals, causing loss of membrane structure and functionality; therefore, LPO is a part of the etiology of many diseases. Such serious consequences of LPO have encouraged studies on the efficacy and mechanisms of action of biological antioxidants, justifying the relevance in the understanding the activity of uremic solutes against $\mathrm{ROO}^{\circ}$. In the crocin bleaching assay, antioxidants compete with crocin for the ROO' radical generated by AAPH thermolysis; therefore, the inhibition of the oxidation of crocin depends on the capacity of the samples to capture this radical species generated in situ. The solutes uric acid, $p$-cresol, phenol and L-tyrosine, and Trolox, were effective in inhibiting the crocin bleaching (Figure 2A, B and C; Tables 2 and 3); it should be noted that only uric acid produced an effect of the same order of magnitude as Trolox. It is interesting to note that the increased circulating levels of uric acid has been cited as a protective mechanism trying to counteract LPO oxidation during atherosclerosis, although this increase has been also associated with an elevated rate of disease and mortality [34].

The relationship between the antioxidant potential of uremic solutes and the ability to prevent biological damage was also assessed by Ujhelyi et al. [14]; the authors showed that plasma ultrafiltrate from CKD patients exhibited $i$ ) a pronounced antioxidant activity, assessed by the ability to inhibit the heme-mediated LDL oxidation (in vitro assay), and ii) protection against endothelial cytotoxicity induced by LDL oxidation. This antioxidant capacity of plasma ultrafiltrate from CKD patients was lost after HD as a consequence of the dialytic removal of some compounds, including the uremic solutes indoxyl sulfate, $p$-cresol, phenol, and uric acid; in addition, it was observed that the retention of other solutes, including L-arginine, creatinine, guanidines, hippuric acid, among others, was not sufficient to prevent the oxidative modification of LDL. The presence or absence of 

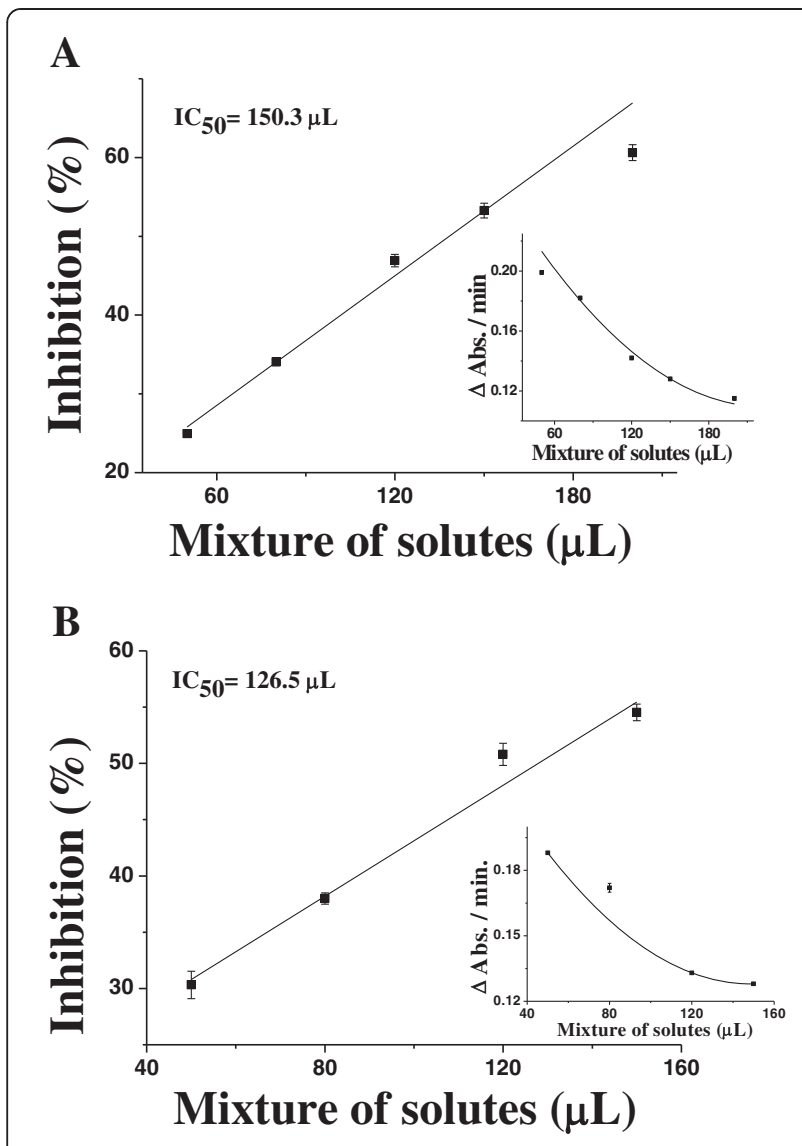

C

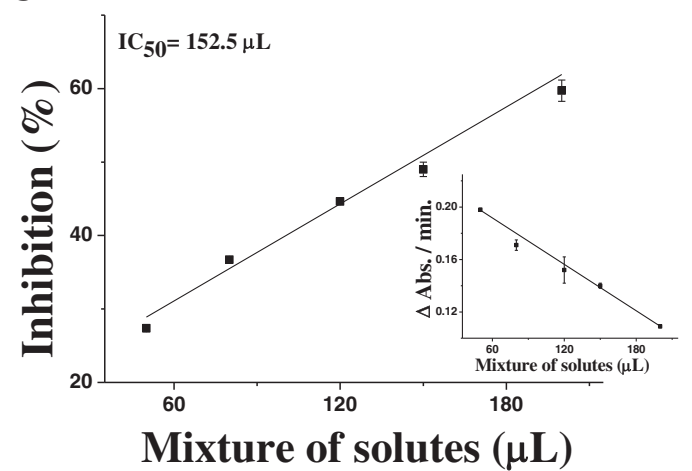

Figure 4 Effects of solute mixtures in the crocin bleaching assay. (A) uric acid plus phenol; (B) uric acid plus p-cresol and (C) phenol plus $p$-cresol. The insets show the mean rates of change of absorbance, at $443 \mathrm{~nm}$, in crocin bleaching plotted against amount of solute mixture added: (A) stock solute mixture with: uric acid (69.0 $\mu \mathrm{mol} / \mathrm{L})$ plus phenol $(11,258.1 \mu \mathrm{mol} / \mathrm{L})$, (B) stock solute mixture with: uric acid $(69.0 \mu \mathrm{mol} / \mathrm{L})$ plus $p$-cresol $(11,623.1 \mu \mathrm{mol} / \mathrm{L})$ (C) stock solute mixture with: phenol $(11,258.1 \mu \mathrm{mol} / \mathrm{L})$ plus $p$-cresol $(11,623.1$ $\mu \mathrm{mol} / \mathrm{L})$; final volume reaction, $2000 \mu \mathrm{L}$. The ROO* scavenging assay was performed in duplicate testes.

antioxidant ability observed by the authors was corroborated by our findings for the most of the uremic solutes. At this time, it is appropriate to quote a sentence of Ujhelyi et al. [52] in response to Meijers and colleagues, "p-cresol can be considered to be a Janus-faced compound with several toxic and some beneficial properties, and it might be a marker of pathologic metabolic processes that lead to the observed enhanced risk of mortality in hemodialysis patients". This Janus-faced feature has been also attributed to other solutes, such as uric acid [53] and indoxyl sulfate [35,54].

Bianchi et al. [42] assessed the oxidative damage of lipids in erythrocytes of CKD patients by chemiluminescence assays for LPO initiated by tert-butyl hydroperoxide $(\mathrm{t}-\mathrm{BOOH})$, which are sensitive and have been used to observe indirectly the previous oxidative stress and diminished endogenous antioxidants [55,56]. When chemiluminescence data from pre- and post-HD patients were compared, no differences were observed, but an increased chemiluminescence was observed when pre-HD patients were compared with healthy subjects, showing a state of oxidative stress in these patients. It is important to note that the crocin bleaching test allows the analysis of the antioxidant effect of uremic solutes, i.e., how much they prevent the LPO process.

Recently, an interesting approach to evaluate the relationship between uremic solutes and oxidative stress was proposed by Oowada et al. [19]: the authors used a common experimental procedure to produce ROS (UV/visible-light photolysis of free radical precursors/ sensitizers), and they made a radar chart based on the recording of the electron spin resonance spectrum using spin traps; this approach was used to assess the scavenging capacity of serum samples. The authors observed that serum samples of CKD patients showed decreased scavenging capacity against ${ }^{\circ} \mathrm{OH}$ and methyl $\left({ }^{\circ} \mathrm{CH}_{3}\right)$ radicals and singlet oxygen $\left({ }^{1} \mathrm{O}_{2}\right)$, increases for $\mathrm{O}_{2}^{--}$and $\mathrm{RO}^{*}$ radicals, and no changes for $\mathrm{ROO}^{\circ}$ radical in comparison to healthy individuals. It is interesting to note that the authors did not explain these changes in the scavenging capacity, but they highlight for the future application of this approach as a tool for clinical uses.

Given that in the body and especially under uremic conditions, there is always a complex mixture of uremic solutes, it would clearly be of interest to analyze the effects of a mixture of the four solutes, uric acid, $p$-cresol, phenol and L-tyrosine, that exhibited significant scavenging capacity towards the three reactive species $\mathrm{ABTS}^{*+}$, $\mathrm{HOCl} / \mathrm{OCl}^{-}$and ROO${ }^{\circ}$. In the $\mathrm{ABTS}^{\circ+}$ and $\mathrm{HOCl} / \mathrm{OCl}^{-}$ scavenging assays carried out with the 4-solutes mixture, it was found that at the $\mathrm{IC}_{50}$, the concentration of each solute was about a quarter of its individual $\mathrm{IC}_{50}$ (Table 4A and B).

In view of the complexity of the crocin bleaching assay, in which antioxidants compete dynamically with the crocin to react with the radical species generated in situ, the mixed-solute in this assay was restricted to binary mixtures. To scavenge ROO', it was need more mass 
Table 5 Relations between the $\mathrm{IC}_{50}$ of the solutes uric acid, phenol and $p$-cresol determined in the crocin bleaching assay, with single solutes or binary mixtures

\begin{tabular}{|c|c|c|c|c|c|c|c|c|c|}
\hline \multirow[t]{2}{*}{$\begin{array}{l}\text { Mixtures of } \\
\text { uremic solutes }\end{array}$} & \multirow[t]{2}{*}{$\begin{array}{l}\text { Volume }(\mu \mathrm{L}) \text { of } \\
\text { solute mixture } \\
\text { needed for } \mathrm{IC}_{50}\end{array}$} & \multicolumn{3}{|c|}{$\begin{array}{l}\text { Concentrations } \\
\text { ( } \mu \text { mol/L) of each } \\
\text { solute in mixture } \\
\text { at } I C_{50}\end{array}$} & \multirow[t]{2}{*}{$\begin{array}{l}\text { Total concentration } \\
\text { of uremic solutes } \\
\text { observed in the } \\
\text { mixture }(\mu \mathrm{mol} / \mathrm{L})\end{array}$} & \multicolumn{3}{|c|}{$\begin{array}{l}\mathrm{IC}_{50}(\mu \mathrm{mol} / \mathrm{L}) \text { of } \\
\text { single solutes }\end{array}$} & \multirow[t]{2}{*}{$\begin{array}{l}\text { Projected total concentration } \\
(\mu \mathrm{mol} / \mathrm{L}) \text { of the binary } \\
\text { mixtures of uremic solutes } \\
\text { from the } I C_{50} \text { of a single } \\
\text { solutes* }\end{array}$} \\
\hline & & $\begin{array}{l}\text { Uric } \\
\text { acid }\end{array}$ & Phenol & $p$-Cresol & & $\begin{array}{l}\text { Uric } \\
\text { acid }\end{array}$ & Phenol & $p$-Cresol & \\
\hline Uric acid + Phenol & 150.3 & 5.18 & 846.04 & --- & 851.22 & 6.90 & 1125.81 & -- & 566.35 \\
\hline $\begin{array}{l}\text { Uric acid + } \\
p \text {-cresol }\end{array}$ & 126.5 & 4.36 & --- & 735.16 & 739.52 & 6.90 & --- & 1162.31 & 584.60 \\
\hline $\begin{array}{l}\text { Phenol + } \\
\text { p-cresol }\end{array}$ & 152.5 & --- & 858.43 & 886.26 & 1744.69 & --- & 1125.81 & 1162.31 & 1144.06 \\
\hline
\end{tabular}

*The projected total concentration at the $\mathrm{IC}_{50}$ of the binary mixtures, for example, uric acid + phenol is $(6.90+1125.81) / 2=566.35$.

of uremic solutes to reach an $\mathrm{IC}_{50}$ value of these mixtures, which was therefore higher than the projected $\mathrm{IC}_{50}$, obtained from the of the $\mathrm{IC}_{50}$ of single solutes (25\% of each, in the binary mixtures) for the same assay (Table 5). Similarly, using the ORAC (oxygen radical absorbance capacity) method, Noguer et al. [57] observed that binary mixtures of uric acid or ascorbic acid with the phenolic compound 3-hydroxyphenylacetic acid showed a diminished antioxidant activity in comparison with the theoretical values obtained from the sum of the activity of each compound individually. Taken together, it can be suggested the existence of an interaction between phenol and/or phenolic derivatives with uric acid or even with other antioxidant compounds. In front of these findings, it seems extremely useful the monitoring the effectiveness of the antioxidant status of biological samples (mixtures), mainly under conditions of altered levels of the endogenous antioxidant network and/or after the employment of exogenous antioxidant therapy.

Considering our findings, the $\mathrm{IC}_{50}$ showed to be a valuable analytical tool, as knowing the values of $\mathrm{IC}_{50}$ for each solute, it was possible to weigh their ROSscavenging capacities in mixtures of solutes. This analysis was accurate and exact for the assays in which the ROS were present in the initial mixture $\left(\mathrm{ABTS}^{\bullet+}, \mathrm{HOCl} /\right.$ $\mathrm{OCl}^{-}$), but was not exact for those in which they were generated in situ (crocin bleaching assay, ROO*). Thus, the application of the $\mathrm{IC}_{50}$ as an analytical tool to mixtures of solutes enables their individual antioxidant activities to be investigated in biological fluids containing such mixtures, over a range of concentrations and in varied pathophysiological states with or without antioxidant therapy, such as those provoked by kidney disease.

\section{Conclusions}

From the results of this study, we can conclude that the same set of uremic solutes, uric acid, $p$-cresol, phenol and L-tyrosine, showed significant antioxidant activity in the $\mathrm{ABTS}^{\bullet+}, \mathrm{HOCl} / \mathrm{OCl}^{-}$and crocin bleaching ( $\mathrm{ROO}^{*}$ capture) assays, albeit with differing efficiencies. The values of $\mathrm{IC}_{50}$ found, in the three assays where the set of four uremic solutes were effective, they were below physiological concentrations, as demonstrated by their behavior both separately or combined. It must be emphasized, however, that for $\mathrm{O}_{2}^{*-}$ and $\mathrm{H}_{2} \mathrm{O}_{2}$, which are extremely important endogenous ROS produced during oxidative stress, no uremic solute showed scavenging capacity.

Thus, it could be interesting to knowledge the behavior $\left(\mathrm{IC}_{50}\right)$ of theoretical mixtures and compare them with real biological samples using, for example, an analytical approach to generate ROS and to monitor their specific scavenging capacities, as the model proposed by Oowada and collaborators [19]. Finally, the combined use of these analytical tools may be useful for the assessment of the oxidative status of CKD and HD patients, as well as to project and to monitor the effectiveness of antioxidant interventions.

\section{Competing interests}

The authors declare that they have no competing interests.

\section{Authors' contributions}

$I L B, A M B$ and OMMFO designed the study and analyzed and interpreted the data. RPA and JFAC carried out the experiments. VOG, CAAF and RSB discussed analyses and contributed to critical reading of the manuscript. ILB, $A M B$ and RPA wrote the manuscript. All authors read and approved the final manuscript.

\section{Acknowledgements}

The authors wish to thank Conselho Nacional de Desenvolvimento Científico e Tecnológico (CNPq), Fundação para o Desenvolvimento da UNESP (FUNDUNESP), Programa de Apoio ao Desenvolvimento Científico da Faculdade de Ciências Farmacêuticas de Araraquara, UNESP (PADC-FCFAraraquara- UNESP) and Fundação de Amparo à Pesquisa do Estado de São Paulo (FAPESP) for the financial support. We also thank Dr. Eduardo M. Cilli (IQ, UNESP, Araraquara) and Dr. Mariza P. de Melo (FZEA, USP, Pirassununga) for valuable discussions.

\section{Author details}

'Department of Clinical Analysis, School of Pharmaceutical Sciences, São Paulo State University - UNESP, Rua Expedicionários do Brasil 1621, Araraquara CEP 14801-902, São Paulo, Brazil. ²Department of Biochemistry and Technological Chemistry, Institute of Chemistry, São Paulo State University - UNESP, Rua Prof. Francisco Degni 55, Araraquara CEP 14800-900, São Paulo, Brazil. 
Received: 18 July 2014 Accepted: 6 March 2015

\section{Published online: 11 April 2015}

\section{References}

1. Meenakshi Sundaram SP, Nagarajan S, Devi AJM. Chronic kidney diseaseeffect of oxidative stress. Chin J Biol. 2014;2014:1-6.

2. Small DM, Coombes JS, Bennett N, Johnson DW, Gobe GC. Oxidative stress, anti-oxidant therapies and chronic kidney disease. Nephrol. 2012;17:311-21.

3. Massy ZA, Stenvinkel P, Drueke TB. The role of oxidative stress in chronic kidney disease. Semin Dial. 2009;22:405-8.

4. Malyszko J. Mechanism of endothelial dysfunction in chronic kidney disease. Clin Chim Acta. 2010;411:1412-20.

5. Satoh M. Endothelial dysfunction as an underlying pathophysiological condition of chronic kidney disease. Clin Exp Nephrol. 2012;16:518-21.

6. Go AS, Chertow GM, Fan D, McCulloch CE, Hsu CY. Chronic kidney disease and the risks of death, cardiovascular events, and hospitalization. N Engl J Med. 2004;23:1296-305.

7. Schiffrin EL, Lipman ML, Mann JF. Chronic kidney disease: effects on the cardiovascular system. Circulation. 2007;116:85-97.

8. Vanholder R, Baurmeister U, Brunet P, Cohen G, Glorieux G, Jankowski J, et al. A bench to beside view of uremic toxins. J Am Soc Nephrol. 2008:19:863-70.

9. Himmelfarb J, Ikizler TA. Hemodialysis. N Engl J Med. 2010;363:1833-45.

10. Kadkhodaee M, Hemmati M, Zahmatkesh M, Ghaznavi R, Mirershadi F, Mahdavi Mazde M, et al. Assessment of plasma antioxidant status in hemodialysis patients. Ther Apher Dial. 2008;12:147-51.

11. Wratten ML, Galaris D, Tetta C, Sevanian A. Evolution of oxidative stress and inflammation during hemodialysis and their contribution to cardiovascular disease. Antioxid Redox Signal. 2002:4:935-44.

12. Glorieux G, Neirynck N, Veys N, Vanholder R. Dialysis water and fluid purity: more than endotoxin. Nephrol Dial Transplant. 2012;27:4010-21.

13. Chen MF, Chang CL, Liou SY. Increase in resting levels of superoxide anion in the whole blood of uremic patients on chronic hemodialysis. Blood Purif. 1998;16:290-300

14. Ujhelyi L, Balla G, Jeney V, Varga Z, Nagy E, Vercellotti GM, et al. Hemodialysis reduces inhibitory effect of plasma ultrafiltrate on LDL oxidation and subsequent endothelial reactions. Kidney Int. 2006;69:144-51.

15. Vanholder R, Van Laecke $S$, Glorieux $G$. What is new in uremic toxicity? Pediatr Nephrol. 2008;23:1211-21.

16. Mayer B, Zitta S, Greilberger J, Holzer H, Reibnegger G, Hermetter A, et al. Effect of hemodialysis on the antioxidative properties of serum. Bioch Biophys Acta. 2003;1638:267-72.

17. Chen T, Liou S, Chang Y. Chemiluminescent analysis of plasma antioxidant capacity in uremic patients undergoing hemodialysis. Ren Fail. 2008;30:843-7.

18. Gerardi GM, Usberti M, Martini G, Albertini A, Sugherini L, Pompella A, et al. Plasma total antioxidant capacity in hemodialyzed patients and its relationships to other biomarkers of oxidative stress and lipid peroxidation. Clin Chem. 2002;40:104-10

19. Oowada S, Endo N, Kameya H, Shimmei M, Kotake Y. Multiple free-radical scavenging capacity in serum. J Clin Biochem Nutr. 2012;51:117-21.

20. Cao G, Prior RL. Comparison of different analytical methods for assessing total antioxidant capacity of human serum. Clin Chem. 1998:44:1309-15.

21. Halliwell B, Gutteridge JMC. The chemistry of free radicals and related 'reactive species'. In: Halliwell B, Gutteridge JMC, editors. Free radicals in biology and medicine. New York: Oxford; 2010. p. 30-78.

22. Re R, Pellegrini N, Proteggente A, Pannala A, Yang M, Rice-Evans C. Antioxidant activity applying improved ABTS radical cation decolorization assay. Free Rad Biol Med. 1999;26:1231-7.

23. Kakkar P, Das B, Viswanayhan PN. A modified spectrophotometric assay of superoxide dismutase. J Biochem Biophys. 1984;21:130-2.

24. Hazra B, Biswas S, Mandal N. Antioxidant and free radical scavenging activity of Spondias pinnata. BMC Complement Altern Med. 2008:8:1-10.

25. Kettle AJ, Winterbourn CC. Assays for the chlorination activity of myeloperoxidase. Methods Enzymol. 1994;233:233:502-12.

26. Dypbukt JM, Bishop C, Brooks WM, Thong B, Eriksson H, Kettle AJ. A sensitive and selective assay for chloramine production by myeloperoxidase. Free Rad Biol Med. 2005;39:1468-77.

27. Zgliczynski JM, Stelmaszynska T, Domanska J, Ostrowski W. Chloramines as intermediates of oxidation reaction of amino acids by myeloperoxidase. Biochem Biophys Acta. 1971;235:419-24.
28. Tubaro F, Ghiselli A, Rapuzzi P, Maiorino M, Ursini F. Analysis of plasma antioxidant capacity by competition kinetics. Free Rad Biol Med. 1998;24:1228-34.

29. Thomas EL, Grisham MB, Jefferson MM. Preparation and characterization of chloramines. Methods Enzymol. 1986;132:569-85.

30. Ching T, Jong J, Bast A. A method for screening hypochlorous acid scavengers by inhibition of the oxidation of 5-thio-2-nitrobenzoic acid: application to antiasthmatic drugs. Anal Biochem. 1994;218:377-81.

31. Ellman GL. Tissue sulfhydryl groups. Arch Biochem Biophys. 1959:82:70-7.

32. Brestel EP. Co-oxidation of luminol and hydrogen peroxide. Implications for neutrophil chemiluminecence. Biochem Biophys Res Commun. 1985;126:482-8.

33. Vanholder R, Glorieux G, Lameire N. European Uremic Toxin Work Group. Uraemic toxins and cardiovascular disease. Nephrol Dial Transplant. 2003;18:463-6.

34. Nieto FJ, Iribarren C, Gross MD, Comstock GW, Cutler RG. Uric acid and serum antioxidant capacity: a reaction to atherosclerosis? Atherosclerosis. 2000;148:131-9.

35. Miyamoto $Y$, Iwao $Y$, Tasaki $Y$, Sato $K$, Ishima $Y$, Watanabe H, et al. The uremic solute indoxyl sulfate acts as an antioxidant against superoxide anion radicals under normal-physiological conditions. FEBS Lett. 2010;584:2816-20.

36. Budavari S, O'Neil MJ, Smith A, Heckelman PE. The Merck Index (an encyclopedia of chemicals, drugs, and biologicals). 14th ed. New Jersey: Merck; 2006.

37. Lussignoli S, Fraccaroli M, Andrioli G, Brocco G, Bellavite P. A microplate based colorimetric assay of the total peroxyl radical trapping capability of human plasma. Anal Biochem. 1999;269:38-44.

38. Mello LD, Kubota LT. Biosensors as a tool for the antioxidant status evaluation. Talanta. 2007;72:335-48.

39. Vellosa JCR, Khalil NM, Gutierres VO, Santos VAFFM, Furlan M, Brunetti IL, et al. Salacia campestris root bark extract: peroxidase inhibition, antioxidant and antiradical profile. Braz J Pharm Sci. 2009;45:99-107.

40. Gülçin I. Comparison of in vitro antioxidant and antiradical activities of $\mathrm{L}$ tyrosine and L-Dopa. Amino Acids. 2007;32:431-8.

41. Chung Y, Wang H, El-Shazly M, Leu YL, Cheng MC, Lee CL, et al. Antioxidant and tyrosinase inhibitory constituents from a desugared sugar cane extract, a byproduct of sugar production. J Agric Food Chem. 2011;59:9219-25.

42. Bianchi PD, Barp J, Thomé FS, Belló-Klein A. Efeito de uma sessão de hemodiálise sobre o estresse oxidativo sistêmico de pacientes renais crônicos terminais. J Bras Nefrol. 2009;31:175-82.

43. Rutgers A, Heeringa P, Kooman JP, Van der Sande FM, Tervaert WC. Peripheral blood myeloperoxidase activity increases during hemodialysis. Kidney Int. 2003;64:760-2.

44. Capeillere-Blandin C, Gausson V, Nguyen AT, Descamps-Latscha B, Drueke T, Witko-Sarsat $\mathrm{V}$. Respective role of uraemic toxins and myeloperoxidase in the uraemic state. Nephrol Dial Transplant. 2006;21:1555-63.

45. Marsche G, Frank S, Hrzenjak A, Holzer M, Dirnberger S, Wadsack C, et al. Plasma-advanced oxidation protein products are potent high-density lipoprotein receptor antagonists in vivo. Circ Res. 2009;104:750-7.

46. Kitabayashi C, Naruko T, Sugioka K, Yunoki K, Nakagawa M, Inaba M, et al. Positive association between plasma levels of oxidized low-density lipoprotein and myeloperoxidase after hemodialysis in patients with diabetic end-stage renal disease. Hemodial Int. 2013;17:557-67.

47. Cadenas E, Davies KJ. Mitochondrial free radical generation, oxidative stress, and aging. Free Rad Biol Med. 2000;29:222-30.

48. Schmidt RJ, Yokota S, Tracy TS, Sorkin MI, Baylis C. Nitric oxide production is low in end-stage renal disease patients on peritoneal dialysis. Am J Physiol. 1999:276:794-7.

49. Baylis C. Arginine, arginine analogs and nitric oxide production in chronic kidney disease. Nat Clin Pract Nephrol. 2006;2:209-20.

50. Barreiros ALBS, David JM, David JP. Estresse oxidativo: relação entre geração de espécies reativas e defesa do organismo. Quim Nova. 2006;29:113-23.

51. Ak T, Gülçin I. Antioxidant and radical scavenging properties of curcumin. Chem Biol Interact. 2008;174:27-37.

52. Ujhelyi L, Balla G, Jeney V, Varga Z, Nagy E, Vercellotti GM, et al. Response to p-Cresol for better or worse: But what are we measuring? Kidney Int. 2006; $70: 232-3$

53. Sautin YY, Johnson RJ. Uric acid: the oxidant - antioxidant paradox. Nucleos Nucleot Nucl. 2008;27:608-19.

54. Praschberger M, Hermann M, Wanner J, Jirovetz L, Exner M, Kapiotis S, et al. The uremic toxin indoxyl sulfate acts as a pro- or antioxidant on LDL oxidation. Free Radic Res. 2014;6:641-8. 
55. Llesuy SF, Milei J, Flecha BSG, Boveris A. Myocardial damage induced by doxorubicins: hydroperoxide-initiated chemiluminescence and morphology. Free Radic Biol Med. 1990:8:259-64.

56. Gonzalez Flecha B, Llesuy S, Boveris A. Hydroperoxide-initiated chemiluminescence: an assay for oxidative stress in biopsies of heart, liver, and muscle. Free Radic Biol Med. 1991;10:93-100.

57. Noguer M, Cerezo AB, Moyá ML, Troncoso AM, García-Parrilla MC. Synergism effect between phenolic metabolites and endogenous antioxidants in terms of antioxidant activity. ACES. 2014;4:258-65.

58. Ordoudi SA, Tsimidou MZ. Crocin Bleaching Assay (CBA) in structure-radical scavenging activity studies of selected phenolic compounds. J Agric Food Chem. 2006;54:9347-56.

59. MacNnamara PJ, Lalka D, Gibaldi M. Endogenous accumulation products and serum protein binding in uremia. J Lab Clin Med. 1981;98:730-40.

60. Simenhoff ML, Asatoor AM, Milne MD, Zilva JF. Retention of aliphatic amines in uraemia. Clin Sci. 1963;25:65-77.

61. Vanholder RC, Desmet RV, Ringoir SM. Assessment of urea and other uremic markers for quantification of dialysis efficacy. Clin Chem. 1992;38:1429-36.

62. Roberts WL, McMillin GA, Burtis CA, Bruns DE. Appendix. In: Burtis CA, Ashwood ER, Bruns DE, editors. Tietz textbook of clinical chemistry and molecular diagnostics. St. Louis, Missouri: Elsevier; 2006.p. 2252-2302.

63. Niwa T, Maeda K, Ohki T, Saito A, Kobayashi K. Gas chromatographic-mass spectrometric analysis for phenolin uremis serum. Clin Chim Acta. 1981;110:51-7.

64. Matsumoto M, Kishikawa H, Mori A. Guanidino compounds in the sera of uremic patients and in the sera and brain of experimental uremic rabbits. Biochem Med. 1976;16:1-8.

65. Farrel PC, Gotch FA, Peters JH, Berridge Jr BJ, Lam M. Binding of hippurate in normal plasma and in uremic plasma pre - and post-dialysis. Nephron. 1978;20:40.

66. Eksborg S, Persson BA, Allgen LG, Bergström J, Zimmerman L, Fürst P. A seletive method for determination of methil-guanidine in biological fluids. Its application in normal subjects and uremic patients. Clin Chim Acta. 1978;82:141-50.

67. Wengle B, Hellstrom K. Volatile phenols in serum of uremic patients. Clin Sci. 1972:43:493-8.

68. Schoots AC, Peeters JAG, Gerlag PGG. Effect of hemodialysis on serum concentration of HPLC-analyzed accumulating solutes in uremia. Nephron. 1989;53:208-17.

69. Salisbury PF, Dunn MS, Murphy EA. Apparent free aminoacids in deproteinized plasma of normal and uremic persons. J Clin Invest. 1957;36:1227-32.

70. Vanholder R, Hoenich N, Ringoir S. Adequacy studies of fistula single-needle dialysis. Am J Kidney Dis. 1987;10:417-26.

\section{Submit your next manuscript to BioMed Central and take full advantage of:}

- Convenient online submission

- Thorough peer review

- No space constraints or color figure charges

- Immediate publication on acceptance

- Inclusion in PubMed, CAS, Scopus and Google Scholar

- Research which is freely available for redistribution 